\title{
Forest modelling in Quebec: Context, challenges and perspectives ${ }^{1}$
}

\author{
by Guy R. Larocque ${ }^{2}$, Daniel Mailly ${ }^{3}$ and Mélanie Gaudreault ${ }^{3}$
}

\begin{abstract}
Forest productivity models are increasingly being used for the computation of allowable cuts and forest management decision-making in Quebec. A workshop was organized in the spring of 2008 to bring together modellers, managers, users and administrators to provide a forum for the exchange of views and opinions on the challenges and future perspectives in forest modelling. Following a series of oral presentations on the various types of models and their application in forest management, workshop participants held discussions on methodology, collaboration and future directions in modelling. The present article offers a summary of the ideas and suggestions generated during the discussions. Among other things, these dealt with the need to design user-friendly models, with known limitations, that could be used with good quality data and for which it would be possible to calculate the bias and forecasting error. Integrating different types of models or their forecasts is another avenue to consider. In order to effectively collaborate and contribute to the advancement of forest modelling, model developers and users must form multidisciplinary teams and develop efficient communication networks to share their knowledge outside of the usual circles. In the future, the development and adjustment of optimization and complex problem resolution methods as well as a greater use of sensitivity and uncertainty analytical methods will have to be emphasized. Finally, much more importance should be given to criteria other than wood fibre, such as biodiversity, habitat, soils and the effect of climate change.
\end{abstract}

Key words: forest modelling, workshop, ACFAS

\section{RÉSUMÉ}

Lutilisation des modèles de productivité forestière est en constante augmentation pour la réalisation des calculs de possibilité forestière et pour la prise de décision en aménagement forestier au Québec. Un colloque a été organisé au printemps 2008 afin que modélisateurs, aménagistes, utilisateurs et gestionnaires puissent échanger sur le contexte, les défis et les perspectives d’avenir de la modélisation forestière. Suite à une série de conférences portant sur différents types de modèles et leur utilisation en aménagement forestier, les participants au colloque ont discuté de la méthodologie, de la collaboration et des orientations futures de la modélisation. Cet article présente les idées et suggestions recueillies lors des discussions. Celles-ci ont entre autres porté sur la nécessité de concevoir des modèles conviviaux, dont les limites d’utilisation sont connues, qui seront utilisés avec des données de qualité et pour lesquels il est possible de calculer le biais et lerreur de prévision. L'intégration de différents types de modèles ou de leurs prévisions est aussi une avenue à considérer. Afin de collaborer efficacement à lavancement de la modélisation forestière, les concepteurs et les utilisateurs des modèles doivent former des équipes multidisciplinaires et développer des réseaux de communication efficaces afin de partager leurs connaissances en dehors des cercles habituels. Dans l'avenir, la mise au point de méthodes doptimisation et de résolution de problèmes complexes et une plus grande utilisation des méthodes d'analyse de sensibilité et d'incertitude

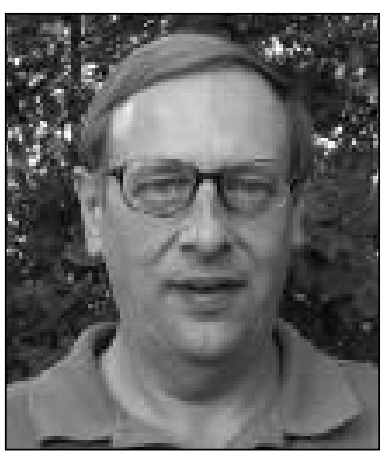

Guy R. Larocque

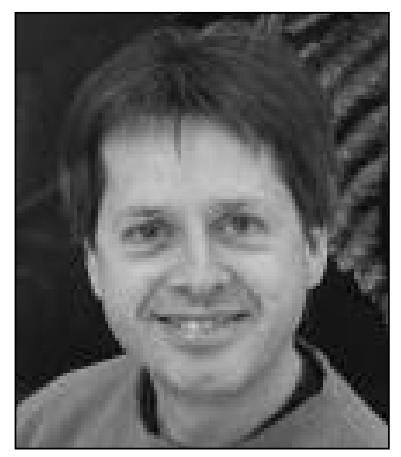

Daniel Mailly

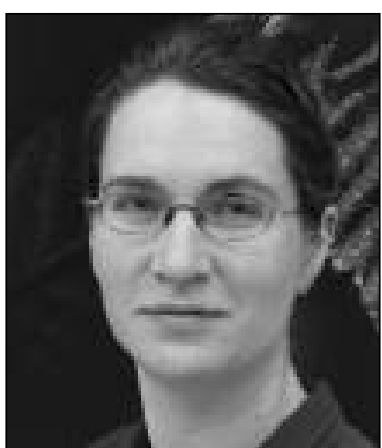

une importance prépondérante devra dorénavant être accordée à des critères autres que la matière ligneuse, tels que la biodiversité, les habitats, les sols et limpact des changements climatiques.

Mots-clés : Modélisation forestière; atelier; ACFAS

\footnotetext{
${ }^{1}$ Summary of the presentations and discussions held at the workshop "How to harmonize different forest modelling approaches in order to improve decision aid tools to support forest management and annual allowable cut computation" that took place at the annual meeting of the Association francophone pour le savoir - ACFAS - in Quebec City on May 8, 2008.

${ }^{2}$ Natural Resources Canada, Canadian Forest Service, Laurentian Forestry Centre, 1055 du P.E.P.S., P.O. Box 10380, Stn. Sainte-Foy, Québec G1V 4C7. Author to whom correspondence should be sent. E-mail: Guy.LaRocque@RNCan-NRCan.gc.ca

${ }^{3}$ Direction de la recherche forestière, Ministère des Ressources naturelles et de la Faune du Québec, 2700, rue Einstein, Québec (Québec) G1P 3W8
} 


\section{Introduction}

Forest productivity models are increasingly being used for allowable cut calculation and decision-making in forest management. Their usefulness continues to grow in response to public pressure over environmental issues, such as changes in biodiversity, the impact of climate change and the application of sustainable forest ecosystem management principles. However, the great variety of models available makes it more difficult for users who must choose the most appropriate tools that suit their needs. A workshop on forest modelling was organized to provide a forum of exchange for modellers, managers, users and administrators. This activity allowed them to learn about recent developments in forest modelling and to express their opinions and needs on the subject (Fig. 1). The workshop was held in Quebec City on May 8, 2008, as part of the conference of the Association francophone pour le savoir (ACFAS; Francophone Association for the Promotion of Knowledge).

The participants first attended a dozen oral presentations on different types of models, which showed the diversity and range of possibilities offered by forest simulation models. Speakers addressed the following themes: integration of ecological, forest, economic and social values into models; development of regional models for forest management applications; modelling of carbon dynamics and accounting; model advancements in Quebec; development of individual-tree models; and application of the concept of ecological rotation ${ }^{4}$. These presentations were followed by discussion sessions that allowed the participants to express their views on 3 main themes: methodologies, collaboration and future directions in forest modelling. In this article we present the ideas and suggestions gathered during the discussion sessions.

\section{Methodologies}

At the beginning of the discussion session, the participants identified the forest models they had previously used (Table 1). Specific questions were then addressed. Participants first discussed the most important characteristics of models that are used as decision-making tools ${ }^{5}$. The characteristics most often cited were ease of use, transparency, absence of or minimal bias, general applicability, knowledge of the range of application, error and uncertainty, and the availability of measurable inputs with the fewest errors possible. It was also mentioned that having access to good-quality data was essential to model adjustment. The user's confidence in models and in the independent variables used as inputs was also discussed. Improvements in the decision-making process in forest management was associated with the development of methods for integrating the forecasts of several models while taking into account the essential linkages between the processes and the spatial and temporal scales.

Several methodologies were then identified as being useful to the integration of the different modelling approaches to help managers make better decisions. Developing user-friendly, flexible software with well-structured documentation was identified as an important way of making the users' task eas-

\footnotetext{
${ }^{4}$ The presentations are available at www.mrnf.gouv.qc.ca/externe/ modelisation/.

${ }^{5}$ Text in italics refers to questions submitted to the participants during the discussions.
}

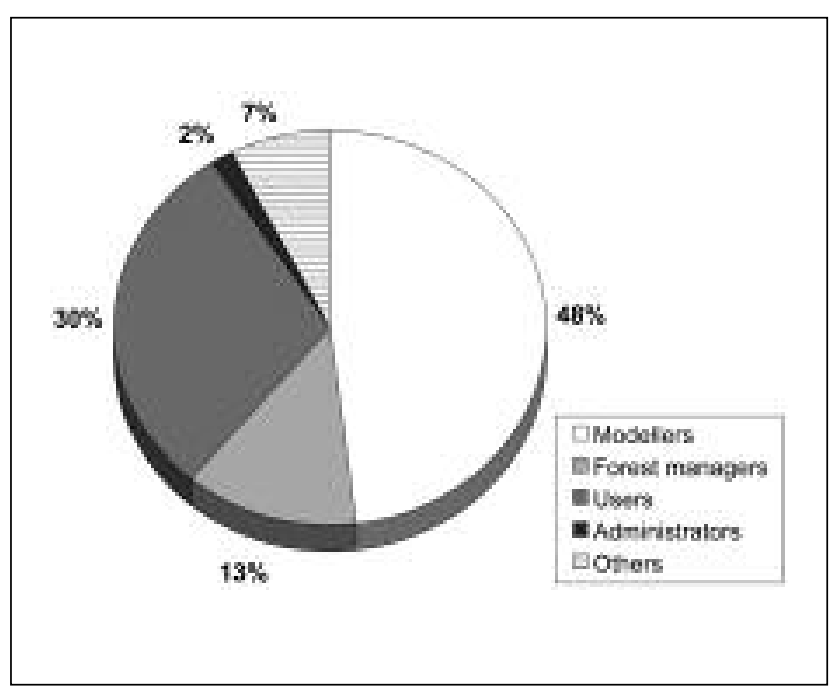

Fig. 1. Audience composition (\%) at the forest modelling workshop.

ier. The integration of different types of models was also proposed as being a favourable approach, with the TRIPLEX model cited as an example. Integrating different types of models could consist of combining empirical growth and process-based models (hybrid models), and should include components for sensitivity and uncertainty analyses. Finally, object-oriented programming languages should be favoured.

Among the key points to remember, the participants mentioned that it was essential to pay attention to data quality, to adequately estimate the bias and the forecasting error, to ensure ease of use, to keep up-to-date with developments elsewhere, to ensure that the methodology remains in line with the desired objective, and to compare the suitability of using provincial models versus local models.

\section{Collaboration}

Under this theme, workshop participants were asked to give their opinion on the characteristics that are essential to a successful collaboration. According to most participants, qualities such as transparency, communication and respect form the basis of good collaboration. Participants also supported the idea of forming multidisciplinary teams composed of persons with complementary expertise, creating favourable teamwork conditions for everybody (win-win situation), while maintaining a common vision and personal affinities. Finally, the participants mentioned that the availability of research funds and the sharing of knowledge and data also constitute key factors to successful collaboration. All of these criteria were perceived as necessary to work effectively and constructively towards the advancement of forest modelling.

A discussion was then initiated on the best form of collaboration to promote the advancement of forest simulation models. Participants first mentioned the importance of developing relationships and communication channels between the model developers and model users. Indeed, the direct involvement of users in the conceptualization process or through regular feedback is required to ensure that the tools under development meet their basic needs and can be used to their full extent. Participants also mentioned the importance of improving linkages among model developers and promoting spontaneous cooperation and knowledge-sharing. In 
Table 1. List of some forest simulation models that participants had already used

Empirical models

Allometric relationships

Stand tables

Stand tables of Pothier and Savard

Stand tables of Boudoux

Forestry allowable cut models

SYLVA II

Growth models

Forest Vegetation Simulator (FVS)

Succession models

SORTIE

ZELIG

Process-based models

TRIPLEX
Lambert, M.-C., C.-H. Ung and F. Raulier. 2005. Canadian national tree aboveground biomass equations. Can. J. For. Res. 35: 1996-2018.

Pothier, D. and F. Savard. 1998. Actualisation des tables de production pour les principales espèces forestières du Québec. Direction des inventaires forestiers, ministère des ressources naturelles du Québec, 183 p.

Boudoux, M. 1978. Tables de rendement empiriques pour lépinette noire, le sapin baumier et le pin gris au Québec. Ministère des Terres et Forêts du Québec, Québec. COGEF. 101 p.

www.mrnf.gouv.qc.ca/produits-services/sylvaii

Stage, A.R. 1973. Prognosis model for stand development. USDA Forest Service, Intermountain Forest and Range Experiment Station, Research Paper INT-137. 32 p.

Teck, R., M. Moeur and B. Eav. 1996. Forecasting ecosystems with the Forest Vegetation Simulator. J. For. 94: 7-10.

Pacala, S.W., C.D. Canham and J.A. Silander, Jr. 1993. Forest models defined by field measurements: I. The design of a northeastern forest simulator. Can. J. For. Res. 23: 1980-1988.

Urban, D.L. 1993. A user's guide to ZELIG version 2 with notes on upgrades from version 1. Department of Forest Sciences, Colorado State University, Fort Collins, CO, USA.

Peng, C., J. Liu, Q. Dang, M.J. Apps and H. Jiang. 2002. TRIPLEX: a generic hybrid model for predicting forest growth and carbon and nitrogen dynamics. Ecol. Model. 153: 109-130. order to develop these new communication channels, several participants suggested the creation of interactive means to exchange and transmit information more rapidly and more broadly. The platforms identified included conferences that bring together the different stakeholders (developers, users and decision-makers), discussion forums, blogs and Internet sites designed for collaborative writing (wiki).

The participants also suggested the establishment of an independent organization that would have the mandate to put together the information on available models and on-going research in Quebec, as well as to disseminate research results. Organizations such as the Conseil de la recherche forestière $d u$ Québec (CRFQ) or the Centre détude sur la forêt (CEF; www.cef-cfr.ca) could be given this type of mandate. Other participants believed that the creation of grant programs focusing on multidisciplinary or integrative projects would be a better way of fostering partnerships among people from different areas. The distribution of these grants could be managed by a funding agency, such as the Fonds québécois de la recherche sur la nature et les technologies (FQRNT; www.fqrnt.gouv.qc.ca), or take on the form of interdepartmental committees. Finally, several participants mentioned the need to create long-term research programs to ensure the stability of funding for modelling and collaboration.

In closing, participants mentioned that the necessary ingredients to promote forest modelling were all present, but that it was vital to increase communication and establish links among all stakeholders, especially between model users and developers.

\section{Future Directions}

Discussions on this theme first focused on current gaps with the tools and approaches in modelling as applied to forestry. Specific applications were mentioned several times, and appeared to have particularly caught the attention of the participants. For instance, elements linked to the methods of optimization and resolution of complex problems and to sensitivity analysis of simulation results were considered of prime importance. They were classified at the same level as issues linked to soil and habitat disturbances, biodiversity and climate change. The following elements were also recognized as being important: expert systems, forest succession, spatialization and localization related to the computation of allowable cuts, forest economics, visualization and modelling at the 
landscape level, prediction of stem quality and silvicultural treatments, sustainable forest management, and model limitations and ethics.

Participants were then invited to look into the future and imagine what will be the role of different modelling approaches in Quebec in 10 to 15 years. Once again, specific approaches were given top priority. Among them, participants mentioned the importance of questions related to habitat and soil quality in future simulation models. In addition, they almost unanimously raised the issue of the change in direction needed for the next series of allowable cut computation so as to take into account values other than wood fibre production. They also highlighted the increasing importance of individual-tree models, of models working at different scales (ecosystem, landscape, regional), and of models used to better forecast the effects of climate change. Modelling the effects of risk, metamodelling $^{6}$, as well as the integration of satellite data and data obtained from Lidar technology will also occupy an increasingly important position.

In the last part of the workshop, the participants were asked to advise a recent graduate who is just beginning to develop a simulation model to be used in decision-making. A recurring element that came out of these discussions was the need to clearly define the final objective before beginning to model a particular problem, and to adequately determine the needs and the context. Some people also mentioned that it was important for the student to be able to identify a simple

\footnotetext{
${ }^{6}$ Meta-modelling is a technique that defines the concepts used to model systems.
}

problem and study it in depth. Another point that was brought up, but with less emphasis, was that the student should be able to explain the difference between the modelling tools used and the quality of model inputs, to validate the model with reliable data, to recognize the limitations of the approach used and to ensure the development of userfriendly graphical interfaces.

\section{Conclusion}

This workshop highlighted the fact that several forest simulation models are used in Quebec and provided an excellent opportunity to stress the importance of having access to such a diversity of models. Modellers as well as model users should henceforth make a special effort to create multidisciplinary teams and share knowledge outside of their usual circles. In addition, it is important that research in forest modelling be supported by adequate and ongoing funding in order to take into account the directions identified by the participants. Finally, primary importance must be given to models using criteria other than wood volume, such as biodiversity, the maintenance of soil nutrient cycles and the carbon sequestration capacity of forest ecosystems.

\section{Acknowledgements}

The authors would like to extend their sincere thanks to Marie Anick Liboiron of Natural Resources Canada for her help in organizing the conference and facilitating the discussions. Stéphane Tremblay, Josianne Deblois, Pierre Bélanger and Johanne Claveau of the Ministère des ressources naturelles et de la Faune du Québec offered helpful comments on an earlier draft of the manuscript. 